Alma Mater Studiorum - Università di Bologna DEPARTMENT OF ECONOMICS

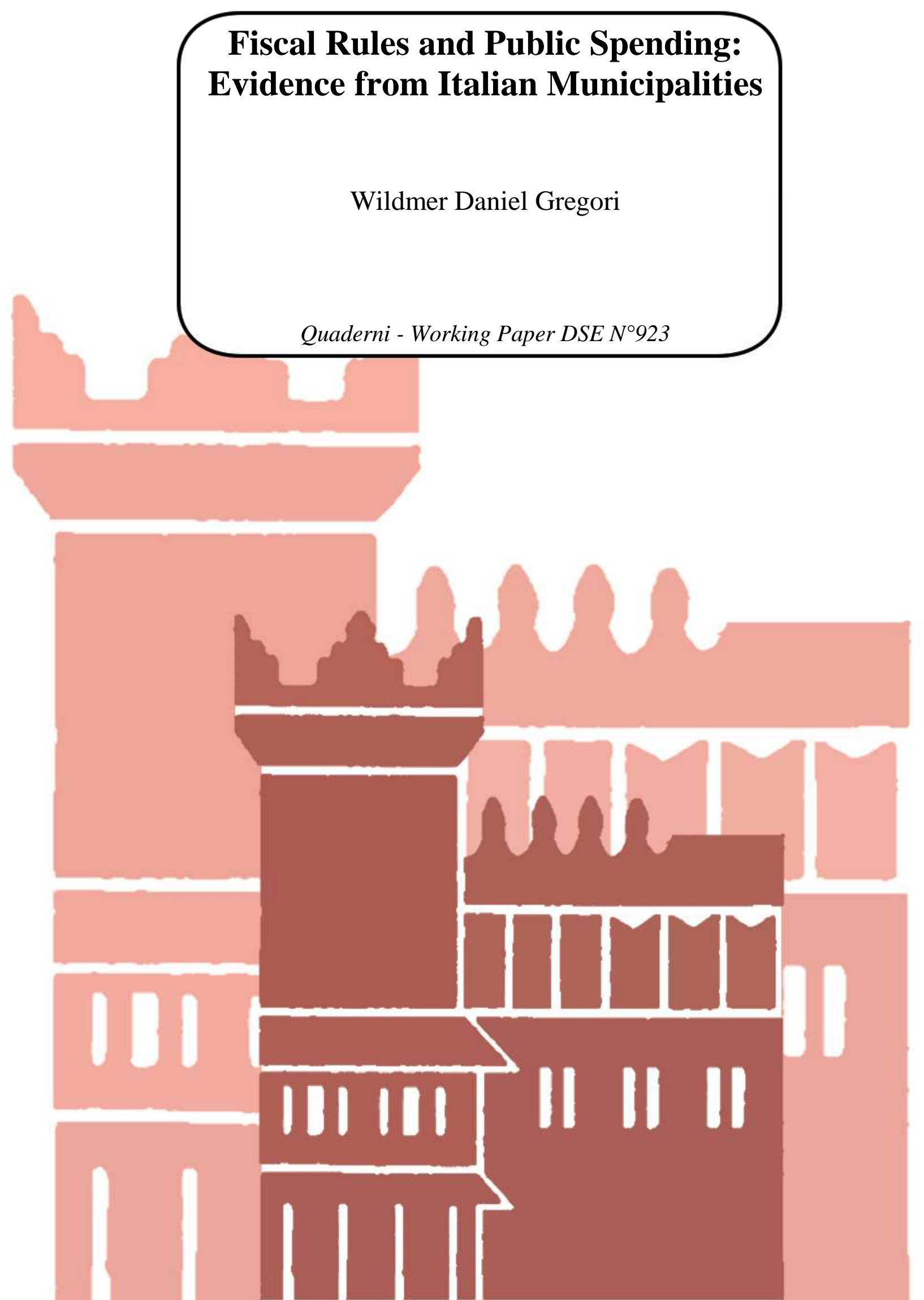




\title{
Fiscal Rules and Public Spending: Evidence from Italian Municipalities
}

\author{
Wildmer Daniel Gregori*
}

February 3, 2014

\begin{abstract}
The aim of this paper is to investigate the extent to which local budget spending composition reacts to fiscal rules variations. I consider the budget of Italian municipalities and exploit specific changes in the Domestic Stability Pact's rules, to perform a difference-in-discontinuities analysis. The results show that not all rules are equally effective: imposing a cap on the total amount of consumption and investment is not as binding as two caps, one specific for consumption and a different one for investment spending. More specifically, the consumption variation is triggered by changes in the level of wages and services spending, while investment relies on infrastructure movements. In addition, there is evidence that when an increase in investment is achieved, there is also a higher budget deficit level.
\end{abstract}

JEL codes: C21, C23, H72, H74, H77.

Key words: Fiscal rules, Difference-in-discontinuities, Public spending, Consumption, Investment, Deficit, Italian Municipalities.

*Department of Economics, University of Bologna. wildmer.gregori@unibo.it. I would like to thank Paolo Manasse, Alberto Zanardi, Massimiliano Marzo, James Rauch, Julie Cullen, Giovanni Prarolo, Valerie Ramey, Fabian Kruger, Nelio Rosa, Matteo Falagiarda and Giorgio Gulino for their useful comments. I also thank participants of the seminar at the University of Bologna, University of California San Diego, Europaeum Workshop in Prague, and the OECD-University Joint conference on "Economics for a Better World". 


\section{Introduction}

Rules for coordinating the financial relationship among different levels of government have the purpose of guaranteeing both macroeconomic stability and financial sustainability. The rationale of fiscal rules stems from two main concepts. The first one is the common pool problem, whereby the presence of imbalances financed by the common pool of national taxes through central transfers generates an incentive for local governments to excessively increase local expenditure (Rodden, 2002). The second concept is related to the fact that whenever a local administration defaults, the national level generally intervenes with transfers of more resources to the local level. This creates an insurance effect and a problem of moral hazard.

In case of Italy, local governments are subject to financial distress. As shown in Figure 1, in the period between 1989 and 2012 there are 460 municipalities where a default occurred ${ }^{1}$. This situation creates social and financial instability at the local level and might also affect the national level if the central government needs to reallocate resources. Indeed, a recent judgment of the European Court of Human Rights point in this direction ${ }^{2}$. In fact, the Court states that when a $m$ suffers financial distress, the Central level has to guarantee for its debt refund. Consequently, fiscal rules play a central role and their ability to affect budget decisions is crucial.

[Figure 1] about here]

Beyond this, subnational rules could also be implemented with the aim of fostering virtuous behaviors. Public spending can focus on consumption or investment. Ganelli and Tervala (2010) affirm that the reallocation of consumption in favor of capital spending might generate welfare gains. In the case of Italian municipalities, the amount of consumption compared to investment spending has changed over time. As shown in Figure 1, the overall consumption of municipalities was $3.96 \%$ of GDP in 1990, while

\footnotetext{
${ }^{1}$ In addition, from the mid-1990s onwards, decentralized governments have made significant recourse to financial tools such as derivatives, mainly Interest Rate Swaps. The number of municipalities that had derivative transaction in 2007 was above 600 (as shown in the "Financial Stability Report" of Banca d'Italia in 2013). They have been exposed to market volatility, which has generated potential liability and, sometimes, financial distress. For instance, Milan signed a contract of derivatives for a total amount of 1.5 billion Euro in 2005 and after a few years had to face a potential loss of 200 million Euro. For this reason, the city of Milan called banks who proposed the transaction to court, arguing that the city had been duped. Moreover, smaller Municipalities have come up against this issue, such as Alessandria and Acqui Terme, who decided to stop paying their derivatives' liabilities to banks.

${ }^{2}$ See the European Court of Human Rights "Case of De Luca vs Italy", n. 43870/04 and the Il Sole 24 Ore's article of the article of September 24th, 2013 entitled "La Corte Ue condanna l'Italia: i debiti dei Comuni falliti vanno pagati".
} 
investment was $2.47 \%$. The distance between these two types of spending subsequently decreased in the following years: in 2005 consumption and investment reached $3.32 \%$ and $3.01 \%$ of GDP, respectively. However, starting from 2006 onwards, this trend has reverted.

[Figure 2 about here]

The aim of this paper is to empirically assess the extent to which public spending of Italian municipalities is affected by fiscal rules. For this purpose, I exploit specific aspects of the Institutional framework. Since 1999 the Italian Government has implemented fiscal rules under the so-called Domestic Stability Pact (hereafter DSP), in order to coordinate and control subnational budget balances. Peculiar features of the DSP give the opportunity to study a natural experiment implementing a difference-in-discontinuity technique.

This paper provides evidence that fiscal rules are not equally effective, but rather they crucially depend on how they are designed. In particular, differences arise concerning whether it is imposed a cap on the overall amount of public spending or if there are two limits, differentiating between consumption and investment. In addition, this paper also highlights the extent to which the budget composition reacts to fiscal rules. When a reduction in consumption is imposed, there is a significant effect of the same sign on the quantity of services offered,whereas while when an increase in investment is allowed, there is a positive variation on the amount of infrastructure spending. Interestingly, there is also a significant increase in the deficit level in the latter case.

This evidence shows the existence of a trade-off, whereby rules that favor investment also cause deficit. The policy maker should take into account these design issues: on one hand only certain rules are actually binding while, on the other hand, rules might have effects that go beyond the initial normative goal.

The reminder of this paper is organized as follows. Section 2 details the related literature, while section 3 analyses the normative framework. Section 4 provides the preliminary analysis and section 5 shows the identification strategy. Sections 6 illustrates the empirical findings, before section 7 concludes.

\section{Literature review}

Fiscal rules are generally justified because they substitute reputation when government policy is discretionary and time-inconsistent. 
In the case of subnational fiscal rules, the debate is controversial, with the theoretical literature suggesting advantages and disadvantages. Authors such as Eichengreen and von Hagen (2004) and Rodden (2004) are in favor of these rules, believing that the scope for subnational fiscal rules is higher when there are severe fiscal imbalances, possibly increased by the decentralization process. In fact, when more functions are delegated to local governments, their spending power rises and imbalances might worsen. In addition, local governments have incentives to free ride on fiscal discipline for different reasons: they can rely on a common pool of national resources (Weingast, 2006); sometimes they are "too big to fail" (Wildasin, 1997), and private creditors on the capital market expect that central government will guarantee for local debts (Dafflon, 2002). Milesi-Ferretti (2004) argues against subnational fiscal rules, suggesting that local rules might lead to "ugly outcomes" for local governments, such as creative accounting and window dressing. Ter-Minassian (Ter-Minassian) affirms that fiscal rules should only be implemented if financial markets or cooperative arrangements across government levels cannot enforce or reach financial discipline.

From an empirical perspective, the DSP has captured the attention of different authors. Patrizii et al. (2006) have addressed the ability of regions and local governments to meet the DSP requirements, whereas Brugnano and Rapallini (2010) evaluate the effects of the DSP on local public borrowing requirements from 1999 to 2005. Bartolini and Santolini (2009) conduct a panel data analysis on the current expenditures of 246 Italian municipalities to capture the impact of the DSP on both the opportunistic behavior of incumbent politicians and the yardstick competition. They show that the introduction of the DSP significantly reduces the level of public spending but strengthens the opportunistic behavior of incumbent politicians in pre-electoral years. Other authors focus on the "effectiveness" approach, in dealing with the impact of fiscal rules on local administrations's ability to achieve fiscal discipline and sustainability. In particular, Balduzzi and Grembi (2010) implement a difference-in-difference methodology on Italian municipalities considering the period 1999-2004 and show that the DSP has a positive and significant impact on current expenditures and taxes' revenues. Galli and Grembi (2010) focus the attention on "special" municipalities ${ }^{3}$ between 1999 and 2000 using a difference-in-difference approach. Their results show that the revenue side is affected when the DSP is imposed, while there are not significant variations in relation to expenditures' decisions. Grembi et al. (2012) analyze Italian Municipalities between 1999 and 2004, implementing a

\footnotetext{
${ }^{3}$ Which are part of the so-called "special status" regions and provinces.
} 
difference-in-discontinuities approach. They highlight that relaxing fiscal rules provokes a deficit bias, shifting from zero to $2 \%$ of total budget, with this variation mainly driven by adjustment on the revenue side.

With respect to the previous literature, this paper contributes to the effectiveness branch of research. The novelty of this work stems from the analysis of specific fiscal rules designed to influence local public spending (i.e. caps on the expenditure side of the budget). It is shown that there are both effective and ineffective fiscal rules. Furthermore, when investment spending increases, there is also a positive reaction in terms of the deficit level.

\section{Normative framework}

Italian municipalities are subject to the Law for Local Authorities ${ }^{4}$, which states goals and duties that have to pursue. Moreover, starting from 1999, the central government has set the DSP in order to honor commitment taken with the European Institutions. Since its introduction, the DSP has implemented different types of rules, particularly: a) a balanced budget, whereby the total amount of revenues has to equal the total amount of expenditures; b) expenditure caps, through which there might be ceilings on total current expenditure or specific expenditure items; c) ceilings on local level revenues, which allow the central government to limit local authorities' ability to increase revenue; d) limits on the stock of debt or the issuance of new debt; e) restrictions on the type of expenditure that can be financed by debt, which usually state that only investment expenditure may be financed through debt (known as "Golden Rule"), requiring a clear definition of investment expenditure to avoid current expenditure being transferred to investments; f) indicators of the ability to service the debt.

Considering that this paper aims to study the extent to which fiscal rules affect local public spending, I am particularly interested in rules designed to have an impact on it. The DSP has implemented this kind of rule twice. In particular, a cap on the total expenditures was set in 2005, which could not be higher than the average spending of the previous three years, augmented by $11.5 \%{ }^{5}$. In the following year, the limit on the overall spending was removed, while different ceilings on current and capital expenditures were

\footnotetext{
${ }^{4}$ Law n. 367/2000. In particular, the actual functions are presented by the DPR 167/1996 and cover a wide range of subjects, such as general administration, justice, local police, public education (up to primary school and part of secondary school), culture, sport, tourism, local public transportation, urban development, social sector, economic development, productive local services.

${ }^{5}$ Further details are shown in the Finance law n. 311, December 30, 2004 and Document of Ministry of Economy and Finance ("Circolare della Ragioneria Generale dello Stato") n. 4 of February 8, 2005.
} 
added. Consumption was the most penalized, with the rule imposing a cut of $6.5 \%$. On the other hand, investment was allowed to increase by $8.1 \%{ }^{6}$. For the purpose of this analysis, I should also highlight DSP rules in the year prior to the introduction of the caps, because I am analyzing the variation of public spending from one year to the next. Thus, in 2004 the DSP imposed the budget balance as target rule.

There is also another crucial element to consider, namely that the number of municipalities subject to the DSP has changed over time. The Pact only constrained municipalities with more than 5,000 inhabitants in 2004 and 2006, while in 2005 the threshold decreased to 3,000, as summarized in Table 1.

[Table 1 about here]

This normative framework provides an opportunity to study the extent to which fiscal rules can affect budget spending decisions at the local level through a natural experiment, as described in the following sections.

\section{Preliminary analysis}

The normative framework shows that the analysis should focus on the period between 2004 and 2006. Data concerning local budgets is derived from the Italian Ministry of the Interior's website ${ }^{7}$ and covets all Italian municipalities. The outcome of interest refers to budget values, and particularly consumption and investment spending ${ }^{8}$. Values are expressed in Euro per-capita and deflated using 2006 as the reference year.

The DSP is set at the national level, although the so-called "special autonomy" provinces and regions are treated differently and therefore had to be excluded from the

\footnotetext{
${ }^{6}$ For both consumption and investment the benchmark level is the one of two years previously. Further details are shown in the Finance law n. 266, December 23, 2005 and Document of Ministry of Economy and Finance ("Circolare della Ragioneria Generale dello Stato") n. 8 of February 17, 2006.

${ }^{7}$ See http://finanzalocale.interno.it/.

${ }^{8}$ Consumption spending is divided into the following categories: Employees, Raw Material, Services and Interests paid on Debt. Investment are detailed in Infrastructures, Goods for internal production, Durable goods, Consulting services, Transfers and Credits. Expenditures are composed by a further category which considers the amount of principal repaid on debt. Current budget revenues are divided in the following categories: Taxes, Fees \& Tarrifs, Current Central Transfers, Current Regional Transfers, Extra-tributary revenues. Capital revenues are split into Alienations, Capital Central Transfers, Capital Regional Transfers, Real estate transfers, Deficit (defined as new loans stipulated by the municipality as shown in the balance sheet in "Titolo V - Entrate derivanti da accensioni di prestiti".). All the budget values represent the accrual basis of accounting.
} 
sample $^{9}$. The dataset also includes information from the National Institute of Statistics about the geographical characteristics of municipalities ${ }^{10}$ which is useful when robustness checks are implemented.

According to the institutional framework, municipalities are grouped in relation to their number of inhabitants: Group A includes those with up to 3,000 people; Group B between 3,000 and 5,000, and Group C above 5,000. Arguably, small and large municipalities might have different behaviors in terms of budget policies and thus it seems reasonable to limit the sample to municipalities with between 1,000 and 7,000 inhabitants ${ }^{11}$.

This preliminary analysis intends to explore consumption and investment spending to provide an intuition of possible DSP effects, with the aim of highlighting different behavior between the three groups during the examined period (2004, 2005 and 2006 are named $t_{1}$, $t_{2}$ and $t_{3}$, respectively). Subsequently, these findings will be further investigated through the empirical analysis (see section 6).

In $t_{2}$, the DSP imposed a cap on total spending to municipalities with more than 3,000 inhabitants. The sum of consumption and investment increased for the non-constrained group (Group A) by $2.8 \%$ from $t_{1}$ to $t_{2}$, while for Groups B and C it decreased by $2.3 \%$ and $3.1 \%$, respctively. Table 2 shows the budget values.

\section{[Table 2 about here]}

In $t_{3}$, municipalities with more than 5,000 inhabitants had to face a different rule. Instead of having just one cap on budget spending, there were two different caps: one on consumption and another on investment. Interestingly, from $t_{2}$ to $t_{3}$, the constrained group (Group C) reported a different trend in terms of budget composition compared to the other groups, as shown in Figure 3. In particular, Group B reached a consumption level that was 1.76 times the investment in 2006. By contrast, Group C did not increase this relationship from $t_{2}$ to $t_{3}$. Such budget spending variation might be due to either a consumption or investment change. Table 2 shows the mean budget values for each group, highlighting that consumption changed between $t_{1}$ and $t_{3}$ by $1.5 \%, 0 \%$ and $-4.5 \%$

\footnotetext{
${ }^{9}$ They have the power to bargain fiscal rules directly with the Central Government. Consequently, municipalities of the autonomous provinces of Trento and Bolzano and the autonomous regions of Sicilia, Sardegna, Valle D'Aosta, Trentino-Alto-Adige and Friuli-Venezia-Giulia have not been considered.

${ }^{10}$ In particular: i) total surface of each Municipality in square kilometers; ii) altitude of the Town hall in meters; iii) altitude zone: Inland mountain, Coastal mountain, Inland Hill, Coastal Hill, Plain; iv) macro-area: Northwest (Piemonte, Lombardia, Liguria), Northeast (Veneto, Emilia-Romagna), Centre ( Toscana, Umbria, Marche, Lazio), South (Abruzzo, Molise, Campania, Puglia, Basilicata, Calabria).

${ }^{11}$ The number of municipalities analyzed is $42 \%$ of the total.
} 
respectively for Group A, B and C, mainly due to variation in services. On the other hand, investment changed by $-6.3 \%,-20.4 \%$ and $-15 \%$ for Group A, B and C, respectively, mostly due to infrastructure spending ${ }^{12}$.

[Figure 3 about here]

As a preliminary comment, there is evidence of a variation in the budget composition during the analyzed period, with the three groups demonstrating different behaviors. This can be due to fiscal rules imposed by the DSP, with the next section focusing on the identification strategy to exploit this possibility accordingly.

\section{$5 \quad$ Identification Strategy}

The institutional framework analyzed in section 3 explained that decisions related to the DSP rules are made by the central government, and are therefore exogenous with respect to local dynamics. Specifically, I would like to assess rules designed to influence budget spending, namely: (i) a total expenditure cap and (ii) consumption and investment caps. For this purpose, I need to identify a treated and control group, and a treatment. Considering Groups $\mathrm{A}, \mathrm{B}, \mathrm{C}$ and $t_{1}, t_{2}, t_{3}$ as defined in the previous section, the analysis involves two steps, each comprising two cases.

As shown in Figure 4, the first step focuses on Groups A and B, which are the control and treated group, respectively, and the threshold is set at 3,000 inhabitants. There are two cases in relation to the period analyzed. Case IA studies $t_{1}$ and $t_{2}$, where the treatment is the imposition of the total expenditure cap to Group B, while Case IB analyzes $t_{2}$ and $t_{3}$, whereby the treatment is the exemption from the total expenditure cap for Group B.

[Figure 4 about here]

The second step relies on results from the first step (as shown in the next section) and considers Group B and C, the control and treated group, respectively, with the threshold set at 5,000 (see Figure 5). As before, there are two cases in relation to the period analyzed. Case IB studies $t_{1}$ and $t_{2}$, where the treatment is the variation of the fiscal rule from "Budget balance" to "Total expenditure cap" for Group C, while Case IIB analyzes $t_{2}$ and $t_{3}$, whereby the treatment is the variation of the fiscal rules from "total expenditure cap" to "consumption and investment caps" for Group C.

\footnotetext{
${ }^{12}$ Mean values have been tested using the t-test and groups have statistically different means at the $95 \%$ confidence interval.
} 
[Figure 5 about here]

The reminder of the section focuses on the formal approach used for the aforementioned cases.

\subsection{General setting}

To assess the causal effect of each fiscal rule (the treatment) on the treated group, it is necessary to consider a minimum set of assumptions to perform the analysis (Angrist et al., 1996). Potential budget outcomes $Y$ are the variables of interest and the actual treatment $D^{13}$ depends on the variable $Z$, which is equal to 1 when a municipality is assigned to the treatment, while $Z=0$ when it is assigned to the control group. The potential budget outcome of municipality $m$ at time $t$ depends on $Z$ and $D$, which can more formally noted as $Y_{m t}=Y_{m}\left(Z_{t}, D_{t}\right)$. Therefore, the outcome is $Y_{m t}(1)$ when the municipality is treated and $Y_{m t}(0)$ when it is not. The following assumptions should be considered:

(i) Stable unit treatment value assumption: the potential outcomes and treatments of unit $m$ are independent from the potential assignment, treatments and outcomes of $n \neq m$. Consequently, when a municipality is subject to the treatment, it should not influence the other one (no general equilibrium effects);

(ii) non-zero average causal effect of $Z$ on $D$ : the probability of treatment must be different between the two groups. Therefore, it is required that whoever is assigned to the treatment actually gets the treatment, or at least part of the component of the treated group. In other words, some level of compliance is necessary ${ }^{14}$;

(iii) the exclusion restriction should hold. Consequently, the assignment only affects the outcome through the treatment;

(iv) monotonicity. No one does the opposite of its assignment, regardless what the assignment is. Thus, the absence of defiers is required. Specifically, a defier would be a municipality that follows the DSP rules without any formal obligation;

(v) random assignment: all municipalities have the same probability of getting the treatment.

It should be noted that assumption (v) cannot hold due to the fact that the assignment is not random, but rather conditioned to the population level. In this case, a Sharp

\footnotetext{
${ }^{13}$ The actual treatment is assumed to be beyond the researcher control (Angrist et al., 1996).

${ }^{14}$ In order to have a high compliance level, the DSP also introduces incentives. Patrizii et al. (2006) show that municipalities are compliant to the DSP.
} 
Regression Discontinuity Design (SRDD) could be implemented, imposing the following assumptions:

(vi) assignment to treatment must only depend on observable pre-intervention variables (i.e. the population level);

(vii) identification of the mean treatment effect is only possible at the threshold;

(viii) the continuity of potential outcome: limits of the expected values have to be identical at the cutoff. In other words, the budget outcomes of municipalities just before and after the cutoff level should be equal.

Under these assumptions, the SRDD can be written as (Angrist and Pischke, 2008):

$$
\lim _{\delta \rightarrow c} E\left[Y_{m} \mid P_{c}<P_{m}<P_{c}+\delta\right]-E\left[Y_{m} \mid P_{c}-\delta<P_{m}<P_{c}\right]=E\left[Y_{m}(1)-Y_{m}(0) \mid P_{m}=P_{c}\right]
$$

where $P_{c}$ is the population at the cutoff level, $\delta$ represents a small number, $Y_{m}$ and $P_{m}$ are the potential budget outcome and population of Municipality $m$. The estimand of this nonparametric estimation strategy is the average causal effect, $E\left[Y_{m}(1)-Y_{m}(0) \mid P_{m}=P_{c}\right]$.

However, assumption (viii) raises some issues. In order to identify the causal effect at the cut-off point, any discontinuity in the relationship between the outcome of interest and the variable determining the treatment status must be fully attributable to the treatment itself. However, there is a confounding discontinuity policy at the cut-offs, due to a change in the wage level of local politicians. In fact, the three groups of municipalities guarantee different wages in relation to the population level, with a jump at 3,000 and 5,000 inhabitants (exactly at the cutoffs). As shown by Gagliarducci and Nannicini (2013), better-paid politicians are able to improve internal efficiency, sizing down the government machine. Consequently, there is a confounding policy that might alter the identification strategy. To overcome this issue, the approach described in the following subsection can be implemented.

\subsection{Difference-in-Discontinuities}

The confounding policy that inhibits the effectiveness of the SRDD strategy is constant over the analyzed period, and thus a Difference-in-Discontinuities (DiDisc) framework can be implemented, as shown in Grembi et al. $(2012)^{15}$. This allows studying the sharp discontinuity at the threshold and, thanks to the Difference-in-Difference (DiD) design,

\footnotetext{
${ }^{15}$ This methodology combines the Difference-in-Difference strategy and a Regression Discontinuity Design.
} 
remove the constant confounding discontinuity policies (i.e. different wage policies among municipalities). The assumptions that should hold are as follows:

(ix) the confounding discontinuity needs to be time invariant. This assumption requires that the effect of wage variations on budget outcome among groups not to vary with time;

(x) the interaction between the treatment and the confounding discontinuity has to be irrelevant. Therefore, different wage policies should not generate a different reaction compared to fiscal rules introduced by the DSP.

Under these assumptions, there is an estimator $\widehat{\phi}$ that identifies the local treatment effect $\phi$ :

$$
\begin{aligned}
\widehat{\phi} \equiv & \left(\lim _{P_{m} \uparrow P_{c}} E\left[Y_{m t} \mid P_{m}, t=t_{1}\right]-\lim _{P_{m} \downarrow P_{c}} E\left[Y_{m t} \mid P_{m}, t=t_{1}\right]\right)+ \\
& -\left(\lim _{P_{m} \uparrow P_{c}} E\left[Y_{m t} \mid P_{m}, t=t_{0}\right]-\lim _{P_{m} \downarrow P_{c}} E\left[Y_{m t} \mid P_{m}, t=t_{0}\right]\right)
\end{aligned}
$$

where $Y_{m t}$ is the potential budget outcome for municipality $m$ at time $t, P_{m}$ is the population level, $t_{1}$ is the year of the treatment and $t_{0}$ is the previous one.

For each case, the assignment to the treatment is given by the dummy $D_{m t}$ which takes the value:

$$
D_{m t}= \begin{cases}0 & \text { if } t=t_{0} \\ 0 & \text { if } P_{m} \leq P_{c}, t=t_{1} \\ 1 & \text { if } P_{m}>P_{c}, t=t_{1}\end{cases}
$$

where $P_{c}$ is the cutoff level. Having described the DiDisc strategy, we can now proceed to the empirical model.

\subsection{Empirical models}

To estimate the DiDisc estimator I use two different methods ${ }^{16}$.

The first one is the "Local Linear Regression" (LLR) method, which fits the data with linear regression functions in a specific sample range. The interval is limited considering a certain distance " $d$ ", thus $P_{m} \in\left[P_{c}-d, P_{c}+d\right]$. The estimated model is:

\footnotetext{
${ }^{16}$ See Imbens and Lemieux (2008) and Grembi et al. (2012).
} 


$$
\begin{aligned}
Y_{m t}= & \alpha_{0}+\alpha_{1} \tilde{P}_{m}+G_{m}\left(\beta_{0}+\beta_{1} \tilde{P}_{m}\right)+ \\
& +t_{1}\left(\gamma_{0}+\gamma_{1} \tilde{P}_{m}+G_{m}\left(\delta_{0}+\delta_{1} \tilde{P}_{m}\right)\right)+\epsilon_{m t}
\end{aligned}
$$

where $Y_{m t}$ is the budget outcome for municipality $m$ at time $t, \tilde{P}_{m}$ is the normalized population size $\left(\tilde{P}_{m}=P_{m}-P_{c}\right), G_{m}$ is a dummy equal to 1 when a city is part of the treated group and 0 otherwise, $t_{1}$ is the treatment year, $\alpha_{0}$ is the intercept and $\epsilon_{m t}$ is the error term. Considering that the treatment is $D_{m t}=G_{m} t_{1}$, the coefficient $\delta_{0}$ is the DiDisc estimator $^{17}$

The second method is the "Spline Polynomial Approximation" (SPA), which relaxes the linearity assumption of the previous method and uses polynomial functions of order $\eta$ to fit the relationship between the outcome of interest $Y_{m t}$ and the population level $P_{c}{ }^{18}$. The estimated model is:

$$
\begin{aligned}
Y_{m t}= & \sum_{n=0}^{\eta}\left(\alpha_{k} \tilde{P}_{m}^{\eta}\right)+G_{m} \sum_{n=0}^{\eta}\left(\beta_{k} \tilde{P}_{m}^{\eta}\right)+ \\
& +t_{1}\left[\sum_{n=0}^{\eta}\left(\gamma_{k} \tilde{P}_{m}^{\eta}\right)+G_{m} \sum_{n=0}^{\eta}\left(\delta_{k} \tilde{P}_{m}^{\eta}\right)\right]+\epsilon_{m t}
\end{aligned}
$$

where the variables and the DiDisc estimator are defined as in the LLR method.

\section{$6 \quad$ Results}

Empirical results are divided between the first (Case IA and IB) and second (Case IIA and IIB) step and focus on consumption and investment spending budget outcomes, showing the DiDisc estimator. The empirical models are represented by equations (3) and (4): the LLR is performed at two different bandwidths, $\mathrm{b}=1,500\left(L L R_{1}\right)$ and $\mathrm{b}=1,300\left(L L R_{2}\right)$, while the SPA is implemented at the second order of the polynomial.

The first step of the analysis is shown in Table 3. The effect of introducing a cap on total spending for municipalities with a population between 3,000 and 5,000 inhabitants

\footnotetext{
${ }^{17}$ Standard errors are clustered at the municipal level and results are controlled considering different bandwidths.

${ }^{18}$ This is true on the right and left hand side of the cutoff level $P_{c}$ and in the treatment year and previous one, for each case analyzed. Standard errors are clustered at the municipal level and robustness checks are performed considering different functional orders.
} 
during the period $t_{1}$ and $t_{2}$ (Case IA) does not produce a significant effect on either consumption or investment for any model specification. Moreover, moving forward of one period (Case IB), and thus studying the effects when the cap is removed, also does not provide any significant effects on both types of spending ${ }^{19}$.

[Table 3 about here]

It can be affirmed that the cap on the overall level of public spending is not capable of significantly influencing the composition of the budget spending. Intuitively, the cap was not sufficiently binding (as shown in section 3, the fiscal rule allowed for a maximum increase of total spending of $11.5 \%$, compared to the average of the previous three years) and both groups reported a behavior that was not significantly different between each other. Therefore, in this framework, the cap on overall spending is not effective and thus it can be seen as a placebo treatment with no effect on budget outcome decisions. These findings are confirmed by the graphical representation of the difference-in-discontinuity approach. In fact, Figure 6 shows the difference between budget outcomes, generated by the difference between $t_{0}$ and $t_{-1}$, between Group A and Group B. At the cutoff level, there is a vertical line to highlight a possible discontinuity. Consumption does not show any discontinuity at the thresholds, while the jump shown by investment is not significant.

[Figure 6 about here]

Before showing the results, it should be noted that there are potentially two contemporaneous treatment. In particular, in the period considered by Case IIA, Group $\mathrm{B}$ is exempted from the DSP in $t_{1}$ and subject to it in $t_{2}$, while there is a variation of the fiscal rule for Group C from "budget balance" to "total expenditure cap". Moving forward one period (Case IIB), Group B is no longer subject to the DSP in $t_{3}$ and there is a further variation from the "budget balance" to "consumption and investment caps" for Group C. In order to disentangle these two treatments, we need to rely on the evidence provided in the first step. The treatment assigned to Group B is claimed not to be effective in both $t_{2}$ and $t_{3}$ and therefore in Case II the treatment is the fiscal rule variation for Group C. Consequently, Group B and C are the control and treated group, respectively.

We can now focus on the results. Case IIA shows the effect of a variation of the fiscal rule for Group C from the "budget balance" to the "total expenditure cap". As shown in

\footnotetext{
${ }^{19}$ The effects are not significant, further deepening the analysis at subcategories of consumption and investment (consumption: wages, raw material, services and interests paid on debt; investment: infrastructures, goods for internal production, durable goods, consulting services, transfers and credits).
} 
the top part of table 4 , there is no evidence for a significant effect of this variation. This result provides evidence in the direction of the first step, with Case IA, Case IB and Case IIA highlighting that the "total expenditure cap" does not have an impact in terms of affecting budget spending composition.

The last analysis (Case IIB) shows the effect of introducing two different caps: one for consumption and another for investment. As further explained in section 3, the fiscal rule imposed a decrease in consumption and allowed for an increase in investment spending. The bottom part of table 4 highlights that the outcome is consistent with the fiscal rule aim: from $t_{2}$ to $t_{3}$ consumption diminished by 28 Euro per-capita, while investment increased by 180 Euro per-capita. Considering subcategories of budget spending, there is evidence that consumption variations are mainly due to movements in wages $(+11$ Euro per-capita) and services (-35 Euro per-capita) spending. In terms of investment, the main subcategory to vary is infrastructure, which accounts for $83.5 \%$ of the overall variation.

Considering that municipalities are only allowed to generate new $\operatorname{debt}^{20}$ to finance investment spending, it seems reasonable to verify what happened to this specific category. For this reason, Table 4 includes a row related to the deficit level for Case IIB. In line with the Golden Rule, the variation of investment and deficit have the same sign and a comparable magnitude, thus providing evidence that an increase in investment fosters a higher deficit level.

[Table 4 about here]

The empirical findings are supported by Figure 7. In Case IIA the behavior of Group 2 and Group 3 is substantially the same, while in Case IIB there is evidence of a discontinuity due to a variation in services and infrastructure spending. In addition, this is also confirmed by the jump in deficit spending.

[Figure 7 about here]

\subsection{Robustness checks}

Smaller municipalities have, on average, a higher level of consumption and investment, which might be due to geographical factors ${ }^{21}$.

\footnotetext{
${ }^{20}$ Which is named deficit, as explained in section 4.

${ }^{21}$ Municipalities situated on the mountains have different issues compared to those located in a plain area, such as higher spending for street maintenance and costs related to the snow. In the empirical analysis there are dummies to control for it.
} 
In order to assess the results' robustness, specific aspects of the municipalities are taken into account, including further peculiarities, as follows: (i) Surface (in $K m^{2}$ ): different territory extensions would likely require a dissimilar budget structure spending. For instance, a wider area would probably include more paved roads and therefore involve higher maintenance costs; (ii) Altitude level (in meters); (iii) Macro-areas dummies: Italy is characterized by economical and cultural differences between the north, center and south, therefore I control for North West, North East, Centre and South areas; (iv) Geographical dummies: factors such as mountains, hills, plains and coasts might affect spending choices; thus, the following dummies are also included: inland mountain, coastal mountain, inland hill, coastal hill, plain.

The LLR model (3) becomes:

$$
\begin{aligned}
Y_{m t}= & \alpha_{0}+\alpha_{1} \tilde{P}_{m}+G_{m}\left(\beta_{0}+\beta_{1} \tilde{P}_{m}\right)+ \\
& +t_{0}\left(\gamma_{0}+\gamma_{1} \tilde{P}_{m}+G_{m}\left(\delta_{0}+\delta_{1} \tilde{P}_{m}\right)\right)+\boldsymbol{\phi X}+\epsilon_{m t}
\end{aligned}
$$

where $\mathbf{X}$ is a vector of the covariates and $\boldsymbol{\phi}$ is a vector of the related coefficients. The SPA model (4) becomes:

$$
\begin{aligned}
Y_{m t}= & \sum_{n=0}^{\eta}\left(\alpha_{k} \tilde{P}_{m}^{\eta}\right)+G_{m} \sum_{n=0}^{\eta}\left(\beta_{k} \tilde{P}_{m}^{\eta}\right)+ \\
& +t_{0}\left[\sum_{n=0}^{\eta}\left(\gamma_{k} \tilde{P}_{m}^{\eta}\right)+G_{m} \sum_{n=0}^{\eta}\left(\delta_{k} \tilde{P}_{m}^{\eta}\right)\right]+\phi \mathbf{X}+\epsilon_{m t}
\end{aligned}
$$

where $\mathbf{X}$ and $\boldsymbol{\phi}$ are defined as in model (5).

Tables 5 and 6 confirm the main findings for the four Cases examined. The only result that it is not robust is the wage variation: there are no significant effects of an impact of the DSP on it.

[Table 5 and Table 6 about here]

\subsection{Comments}

Through the empirical analysis, it has been possible to show that the Domestic Stability Pact is a vehicle for the central government to implement different kinds of local fiscal rules. Specifically, the cap on total spending did not have a significant effect on the budget 
composition either for municipalities that were not subject to the DSP the year before its implementation (as shown in Case IA and Case IB) or those already constrained (Case IIA). It is possible that the policy maker wanted to implement a more binding rule and for this reason changed it in the following year $\left(t_{3}\right)$, imposing different caps on consumption and investment spending. This new fiscal rule was able to significantly influence budget composition, generating a negative variation in the amount of services provided by more than $3 \%$ of the total budget, as well an increase in infrastructure spending by about $15 \%$ (compared to the unconstrained municipalities).

\section{$7 \quad$ Final remarks}

Coordination rules between state and local government levels are fundamental to guarantee overall sound public finance. Unsurprisingly, the European integration process considers fiscal rules as a central subject for stability and growth purposes. This paper studies the effects of the Domestic Stability Pact on Italian municipalities budget composition and thanks to the peculiar framework that characterizes the Pact, has been able to perform a natural experiment implementing a Difference-in-Discontinuity design. The analysis provides two main contributions.

Firstly, there is a discrimination between effective and ineffective fiscal rules. What emerges from the analysis is that the DSP is not effective per se, but rather the kind of fiscal rule implemented is crucial. In fact, it has been shown that imposing a cap on the overall level of current and capital expenditure does not affect budget decisions. Interestingly, imposing separate caps on consumption and investment spending creates an effective boundary, capable of affecting budget composition.

Secondly, effective fiscal rules do not equally affect all the types of spending. In particular, imposing a cut on consumption generates a decrease in the amount of services provided. Allowing for an increase in investment creates an increase in both infrastructure spending and the deficit level.

Therefore, fiscal rules set at the national level are able to significantly affect spending choices at the local level, both in statistical and economic terms. This evidence shows the existence of a trade-off, whereby rules that favor investment also cause a deficit. The policy maker should take into account these design issues: on one hand, only certain rules are actually binding and, on the other hand, rules might have effects that go beyond the initial normative goal. 


\section{References}

Acconcia, A., G. Corsetti, and S. Simonelli (2011). Mafia and public spending: Evidence on the fiscal multiplier from a quasi-experiment. CEPR, Discussion Paper 8305.

Alesina, A., F. R. Campante, and G. Tabellini (2008). Why is fiscal policy often procyclical? Journal of the European Economic Association 6(5), 1006-1036.

Alesina, A. and A. Drazen (1991). Why are stabilizations delayed? The American Economic Review, 1170-1188.

Alesina, A. and R. Perotti (1994). The political economy of budget deficits. National Bureau of Economic Research, Working Paper 4637.

Ambrosanio, M. F. and M. Bordignon (2007). Internal stability pacts: The european experience. European Economic Governance Monitor, Papers.

Angrist, J. D. and J.-S. Pischke (2008). Mostly harmless econometrics: An empiricist's companion. Princeton University Press.

Balassone, F. and D. Franco (2000). Public investment, the stability pact and the âĂŸgolden ruleâĂŹ. Fiscal studies 21(2), 207-229.

Balduzzi, P. and V. Grembi (2010). Compliance vs. effectiveness: Assessing the role of fiscal rules.

Barro, R. J. (1989). The ricardian approach to budget deficits. The Journal of Economic Perspectives 3(2), 37-54.

Bartolini, D. and R. Santolini (2009). Fiscal rules and the opportunistic behaviour of the incumbent politician: Evidence from italian municipalities. CESifo Group Munich.

Bastos, P., L. Castro, J. Cristia, and C. Scartascini (2011). Does energy consumption respond to price shocks? evidence from a regression-discontinuity design. InterAmerican Development Bank Working Paper Series No. IDB-WP-234.

Brugnano, C. and C. Rapallini (2010). Il patto di stabilità interno per i comuni: una valutazione con i certificati dei conti consuntivi. Economia pubblica.

Dafflon, B. (2002). Local public finance in europe: Balancing the budget and controlling debt. Edward Elgar Publishing. 
Eichengreen, B. and J. von Hagen (2004). Fiscal policy and monetary union: Is there a tradeoff between federalism and budgetary restrictions? Journal of Economic Theory 114(2), 198-230.

Gagliarducci, S. and T. Nannicini (2013). Do better paid politicians perform better? disentangling incentives from selection. Journal of the European Economic Association 11(2), 369-398.

Galli, E. and V. Grembi (2010). Assessing degrees of fiscal rules. mimeo presented at The 7th Public Economics At the Regional and Local level (PEARL) Conference, Turin, April, 2010.

Ganelli, G. and J. Tervala (2010). Public infrastructures, public consumption, and welfare in a new-open-economy-macro model. Journal of Macroeconomics 32(3), 827-837.

Giuriato, L. and F. Gastaldi (2009). The domestic stability pact in italy: a rule for discipline? University Library of Munich, Germany.

Grembi, V., T. Nannicini, and U. Troiano (2012). Policy responses to fiscal restraints: A difference-in-discontinuities design. IZA Discussion Paper.

Imbens, G. W. and T. Lemieux (2008). Regression discontinuity designs: A guide to practice. Journal of Econometrics 142(2), 615-635.

Krueger, A. (2002). Crisis prevention and resolution: lessons from argentina. speech at the National Bureau of Economic Research conference on The Argentina Crisis, NBER, Cambridge MA, July.

Lucas, R. E. and N. L. Stokey (1983). Optimal fiscal and monetary policy in an economy without capital. Journal of monetary Economics 12(1), 55-93.

Manasse, P. (2007). Deficit limits and fiscal rules for dummies. IMF Staff Papers 54(3), $455-473$.

Milesi-Ferretti, G. M. (2004). Good, bad or ugly? on the effects of fiscal rules with creative accounting. Journal of Public Economics 88(1), 377-394.

Patrizii, V., C. Rapallini, and G. Zito (2006). I patti di stabilita interni. Rivista di diritto finanziario e scienza delle finanze 65, 156-189. 
Persson, T. and L. E. Svensson (1989). Why a stubborn conservative would run a deficit: Policy with time-inconsistent preferences. The Quarterly Journal of Economics 104(2), $325-345$.

Rodden, J. (2002). The dilemma of fiscal federalism: grants and fiscal performance around the world. American Journal of Political Science, 670-687.

Rodden, J. (2004). Comparative federalism and decentralization: On meaning and measurement. Comparative Politics, 481-500.

Romer, C. D. and D. H. Romer (2010). The macroeconomic effects of tax changes: Estimates based on a new measure of fiscal shocks. American Economic Review 100, 763-801.

Serrato, J. C. and P. Wingender (2010). Estimating local fiscal multipliers. University of California at Berkeley, mimeo.

Sutherland, D., R. Price, and I. Joumard (2005). Fiscal rules for sub-central governments: Design and impact. OECD Publishing.

Ter-Minassian, T. Fiscal rules for subnational governments: can they promote fiscal discipline? OECD Journal on Budgeting 6(3), 111.

Weingast, B. (2006). Second generation fiscal federalism: implications for decentralized democratic governance and economic development. SSRN 1153440.

Wildasin, D. E. (1997). Externalities and bailouts: hard and soft budget constraints in intergovernmental fiscal relations. World Bank Publications 1843.

Zanardi, A. (1997). Federalismo fiscale: si riparte? La finanza pubblica italiana, 127-155. 


\section{A Tables}

Table 1: Fiscal rules imposed by the Domestic Stability Pact to Italian Municipalities.

\begin{tabular}{llll}
\hline Year & Group A & Group B & Group C \\
\hline$t_{1}$ & None & None & Budget balance \\
$t_{2}$ & None & Total expenditure cap & Total expenditure cap \\
$t_{3}$ & None & None & Consumption and Investment caps \\
\hline
\end{tabular}

Notes. $t_{1}, t_{2}$ and $t_{3}$ are respectively years 2004, 2005 and 2006. Group A, Group B and Group $\mathrm{C}$ represent, respectively, municipalities with a population below 3,000 , between 3,000 and 5,000, above 5,000 inhabitants. 


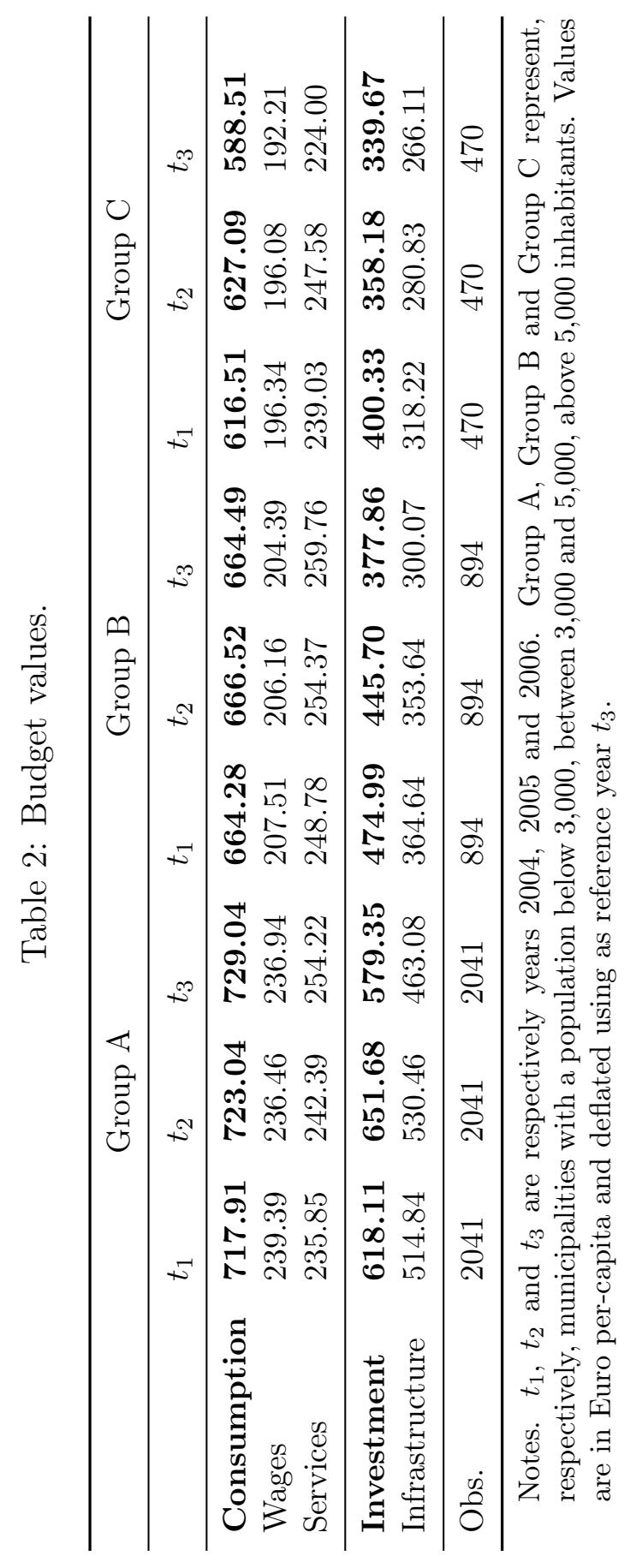


Table 3: Domestic Stability Pact effects in Case I.

\begin{tabular}{lccc}
\hline & $L L R_{1}$ & $L L R_{2}$ & $S P A$ \\
\hline Case IA & & & \\
Consumption & 6.78 & 7.54 & 7.70 \\
& $(9.32)$ & $(10.58)$ & $(11.54))$ \\
Investment & 90.74 & 111.72 & 74.46 \\
& $(68.40)$ & $(74.20)$ & $(93.21)$ \\
\hline
\end{tabular}

\section{Case IB}

\begin{tabular}{lccc} 
Consumption & 2.07 & 2.81 & -5.59 \\
& $(8.06)$ & $(9.31)$ & $(12.50)$ \\
Investment & 4.62 & -22.04 & -85.55 \\
& $(63.52)$ & $(65.61)$ & $(87.76)$ \\
\hline Obs. & 4,078 & 3,446 & 5,870 \\
\hline
\end{tabular}

Notes. Case I refers to Municipalities between 1,000 and 5,000 inhabitants. Case IA considers $t_{1}$ and $t_{2}$ while Case IB analyzes $t_{2}$ and $t_{3} . \quad L L R_{1}$ and $L L R_{2}$ are Local Linear Regressor methods as in equation (3), with a bandwidth of respectively 1,500 and 1,300. SPA is the Spline Polynomial Approximation method of order 2, as in equation (4), and considers all the Municipalities. Values are in Euro per-capita and deflated using $t_{3}$ as reference year. Robust standard errors are in parenthesis and are clustered at the Municipality level. Significance at the $10 \%$ level is represented by *, at the $5 \%$ level by $* *$, at the $1 \%$ level by $* * *$. 
Table 4: Domestic Stability Pact effects in Case II.

\begin{tabular}{lccc}
\hline & $L L R_{1}$ & $L L R_{2}$ & $S P A$ \\
\hline Case IIA & & & \\
Consumption & 9.60 & -2.05 & 4.69 \\
& $(9.49)$ & $(12.62)$ & $(15.77)$ \\
Investment & 4.44 & 6.70 & -44.68 \\
& $(80.13)$ & $(90.19)$ & $(119.15)$ \\
\hline Case IIB & & & \\
Consumption & $-27.97^{* * *}$ & $-23.03^{*}$ & $-28.54^{*}$ \\
Wages & $(10.20)$ & $(11.84)$ & $(14.61)$ \\
& $11.03^{* * *}$ & $12.93^{* * *}$ & $10.73^{* *}$ \\
Services & $(3.00)$ & $(3.53)$ & $(4.40)$ \\
& $-35.40^{* * *}$ & $-34.05^{* * *}$ & $-37.22^{* * *}$ \\
Investment & $(6.72)$ & $(7.67)$ & $(9.49)$ \\
& $179.58^{* * *}$ & $188.45^{* *}$ & $193.83^{* *}$ \\
Infrastructure & $(69.04)$ & $(76.66)$ & $(93.59)$ \\
& $149.97^{* * *}$ & $164.44^{* * *}$ & $171.69^{* *}$ \\
Deficit & $(54.03)$ & $(60.12)$ & $(73.21)$ \\
& $103.22^{* *}$ & $110.40^{* *}$ & $141.07^{* *}$ \\
& $(41.28)$ & $(46.17)$ & $(56.96)$ \\
\hline Obs. & 1,880 & 1,618 & 2,728 \\
\hline
\end{tabular}

Notes. Case II refers to Municipalities between 3,000 and 7,000 inhabitants. Case IIA considers $t_{1}$ and $t_{2}$ while Case IIB analyzes $t_{2}$ and $t_{3} . L L R_{1}$ and $L L R_{2}$ are Local Linear Regressor methods as in equation (3), with a bandwidth of respectively 1,500 and 1,300. SPA is the Spline Polynomial Approximation method of order 2, as in equation (4), and considers all the Municipalities. Values are in Euro per-capita and deflated using $t_{3}$ as reference year. Robust standard errors are in parenthesis and are clustered at the Municipality level. Significance at the $10 \%$ level is represented by $*$, at the $5 \%$ level by $* *$, at the $1 \%$ level by $* * *$. 
Table 5: Robustness checks in Case I.

\begin{tabular}{lccc}
\hline & $\begin{array}{c}\text { LLR } \\
(\mathrm{b}=1,500)\end{array}$ & $\begin{array}{c}\text { LLR } \\
(\mathrm{b}=1,300)\end{array}$ & $\begin{array}{c}\text { Spline } \\
(\text { order 2) }\end{array}$ \\
\hline Case IA & & & \\
Consumption & 3.21 & 4.78 & 2.28 \\
& $(9.87)$ & $(11.09)$ & $(11.48)$ \\
Investment & 56.86 & 74.74 & 37.72 \\
& $(68.01)$ & $(73.31)$ & $(93.26)$ \\
\hline Case IB & & & \\
& & & \\
Consumption & -2.09 & -1.19 & -8.66 \\
& $(7.95)$ & $(9.22)$ & $(12.28)$ \\
Investment & -35.89 & -56.85 & -115.28 \\
& $(63.58)$ & $(66.02)$ & $(88.55)$ \\
\hline Obs. & 4,078 & 3,446 & 5,870 \\
\hline
\end{tabular}

Notes. Case I refers to Municipalities between 1,000 and 5,000 inhabitants. Case IA considers $t_{1}$ and $t_{2}$ while Case IB analyzes $t_{2}$ and $t_{3} . L L R_{1}$ and $L L R_{2}$ are Local Linear Regressor methods as in equation (5), with a bandwidth of respectively 1,500 and 1,300 . SPA is the Spline Polynomial Approximation method of order 2, as in equation (6), and considers all the Municipalities. Values are in Euro per-capita and deflated using $t_{3}$ as reference year. Robust standard errors are in parenthesis and are clustered at the Municipality level. Significance at the $10 \%$ level is represented by $*$, at the $5 \%$ level by ${ }^{* *}$, at the $1 \%$ level by $* * *$. 
Table 6: Robustness checks in Case II.

\begin{tabular}{lccc}
\hline & $\begin{array}{c}\mathrm{LLR} \\
(\mathrm{b}=1,500)\end{array}$ & $\begin{array}{c}\text { LLR } \\
(\mathrm{b}=1,300)\end{array}$ & $\begin{array}{c}\text { Spline } \\
(\text { order } 2)\end{array}$ \\
\hline Case IIA & & & \\
Consumption & 6.84 & -4.86 & 4.42 \\
& $(9.59)$ & $(12.74)$ & $(16.13)$ \\
Investment & -26.75 & -29.78 & -77.15 \\
& $(79.36)$ & $(89.42)$ & $(119.29)$ \\
\hline Case IIB & & & \\
Consumption & $-32.32^{* * *}$ & $-27.57^{* *}$ & $-29.68^{* *}$ \\
& $(10.44)$ & $(12.18)$ & $(15.03)$ \\
Wages & 4.57 & 5.22 & 4.65 \\
Services & $(2.90)$ & $(3.35)$ & $(4.21)$ \\
& $-30.57^{* * *}$ & $-28.19^{* * *}$ & $-30.33^{* * *}$ \\
Investment & $(6.76)$ & $(7.72)$ & $(9.61)$ \\
& $142.38^{* *}$ & $144.22^{*}$ & $156.04^{*}$ \\
Infrastructure & $(68.75)$ & $(76.37)$ & $(93.41)$ \\
& $119.25^{* *}$ & $127.30^{* *}$ & $141.68^{*}$ \\
Deficit & $(53.43)$ & $(59.36)$ & $(72.91)$ \\
& $97.15^{* *}$ & $102.67^{* *}$ & $134.51^{* *}$ \\
\hline Obs. & $(41.58)$ & $(46.48)$ & $(57.23)$ \\
\hline
\end{tabular}

Notes. Case II refers to Municipalities between 3,000 and 7,000 inhabitants. Case IIA considers $t_{1}$ and $t_{2}$ while Case IIB analyzes $t_{2}$ and $t_{3} . L L R_{1}$ and $L L R_{2}$ are Local Linear Regressor methods as in equation (5), with a bandwidth of respectively 1,500 and 1,300. SPA is the Spline Polynomial Approximation method of order 2, as in equation (6), and considers all the Municipalities. Values are in Euro per-capita and deflated using $t_{3}$ as reference year. Robust standard errors are in parenthesis and are clustered at the Municipality level. Significance at the $10 \%$ level is represented by $*$, at the $5 \%$ level by $* *$, at the $1 \%$ level by $* * *$. 


\section{B Figures}

Figure 1: Number of default of Italian Municipalities between 1989 and 2012 by Regions. Source: Corte dei Conti.

\begin{tabular}{|c|c|c|c|c|c|c|c|c|c|c|c|c|c|c|c|c|c|c|c|c|c|c|c|c|c|}
\hline & 1989 & 1990 & 1991 & 1992 & 1993 & 1994 & 1995 & 1996 & 1997 & $\mid 1998$ & 1999 & 2000 & 2001 & 2002 & 2003 & 2004 & 2005 & 2006 & 2007 & 2008 & 2009 & 2010 & 2011 & 2012 & \\
\hline Piemonte & & 1 & 2 & 1 & 1 & & & & & & & & & & & & & & & & & & & & 5 \\
\hline Lombardia & & 3 & 3 & 5 & 1 & 1 & & & & & 1 & & & & & & & & & & & & 1 & & 15 \\
\hline Liguria & 1 & & & 2 & & & & & & & & & & & & & & & & & & & 1 & & 4 \\
\hline Veneto & 1 & & & 1 & & & & 1 & & & & & & & & & & & & & & & & & 3 \\
\hline Emilia Romagna & 1 & & 4 & 1 & & 1 & & & 1 & & & & & & & & & & & & & & & & 8 \\
\hline Toscana & 3 & 1 & & & & & & & & & & & & & & & & & & & & & 1 & & 5 \\
\hline Umbria & 2 & 1 & & & & 1 & & & & & & & & & & & & & & & & & & & 4 \\
\hline Marche & 2 & 1 & 1 & & & 1 & & & & & & & & & & 1 & & & & & & & & & 6 \\
\hline Lazio & 7 & 2 & 5 & 2 & 7 & 3 & 3 & 2 & & 1 & & 2 & & 1 & & & 1 & 1 & & 1 & 2 & 2 & 1 & & 43 \\
\hline Abruzzo & 6 & 1 & 1 & 4 & 1 & 1 & 3 & & & & & & & & & & & & & & 1 & & & & 18 \\
\hline Molise & 4 & 4 & & 1 & 2 & 1 & & & & & & & & & & & & & & & 1 & 2 & & & 15 \\
\hline Campania & 18 & 18 & 10 & 12 & 22 & 14 & 2 & 1 & 5 & & 2 & 1 & & 1 & 1 & 1 & & 2 & & 1 & & 3 & 4 & 3 & 121 \\
\hline Puglia & 21 & 4 & 2 & 4 & 2 & & 1 & & & & & & & & & & & & 1 & & & & & & 35 \\
\hline Basilicata & 4 & 3 & 3 & 1 & 3 & 2 & 2 & 1 & & & & & & & & & & & & & & & & & 19 \\
\hline Calabria & 51 & 22 & 13 & 10 & 11 & 7 & 2 & 3 & 1 & & 1 & & 1 & 1 & 1 & & & & & 3 & & 1 & 1 & 2 & 131 \\
\hline Sicilia & 2 & 3 & 1 & 2 & 2 & 6 & 3 & 1 & & & 1 & & & & & & 2 & 1 & & & & & 1 & & 25 \\
\hline \multirow[t]{2}{*}{ Sardegna } & 2 & & & & & & & & & & & & & 1 & & & & & & & & & & & 3 \\
\hline & 125 & 64 & 45 & 46 & 52 & 38 & 16 & 9 & 7 & 1 & 5 & 3 & 1 & 4 & 2 & 2 & 3 & 4 & 1 & 5 & 4 & 8 & 10 & 5 & 460 \\
\hline
\end{tabular}


Figure 2: Italian Municipalities spending as a percentage of GDP (period between 1990 and 2010). Source: Istat, author's calculations.

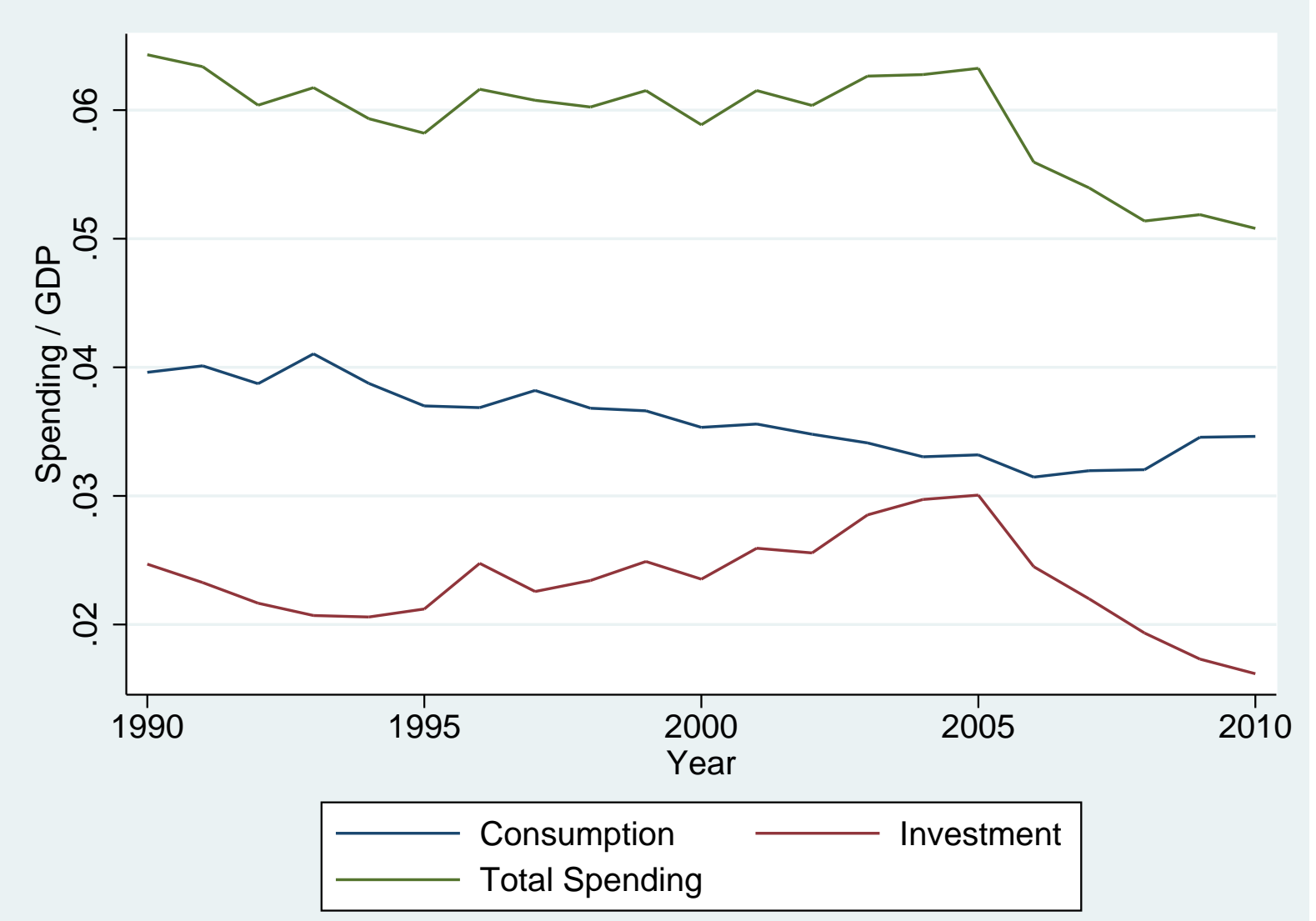


Figure 3: Level of Consumption over Investment for the three groups of Municipalities in the period between 2004 and 2006. Source: Ministry of the Interior, author's calculations.

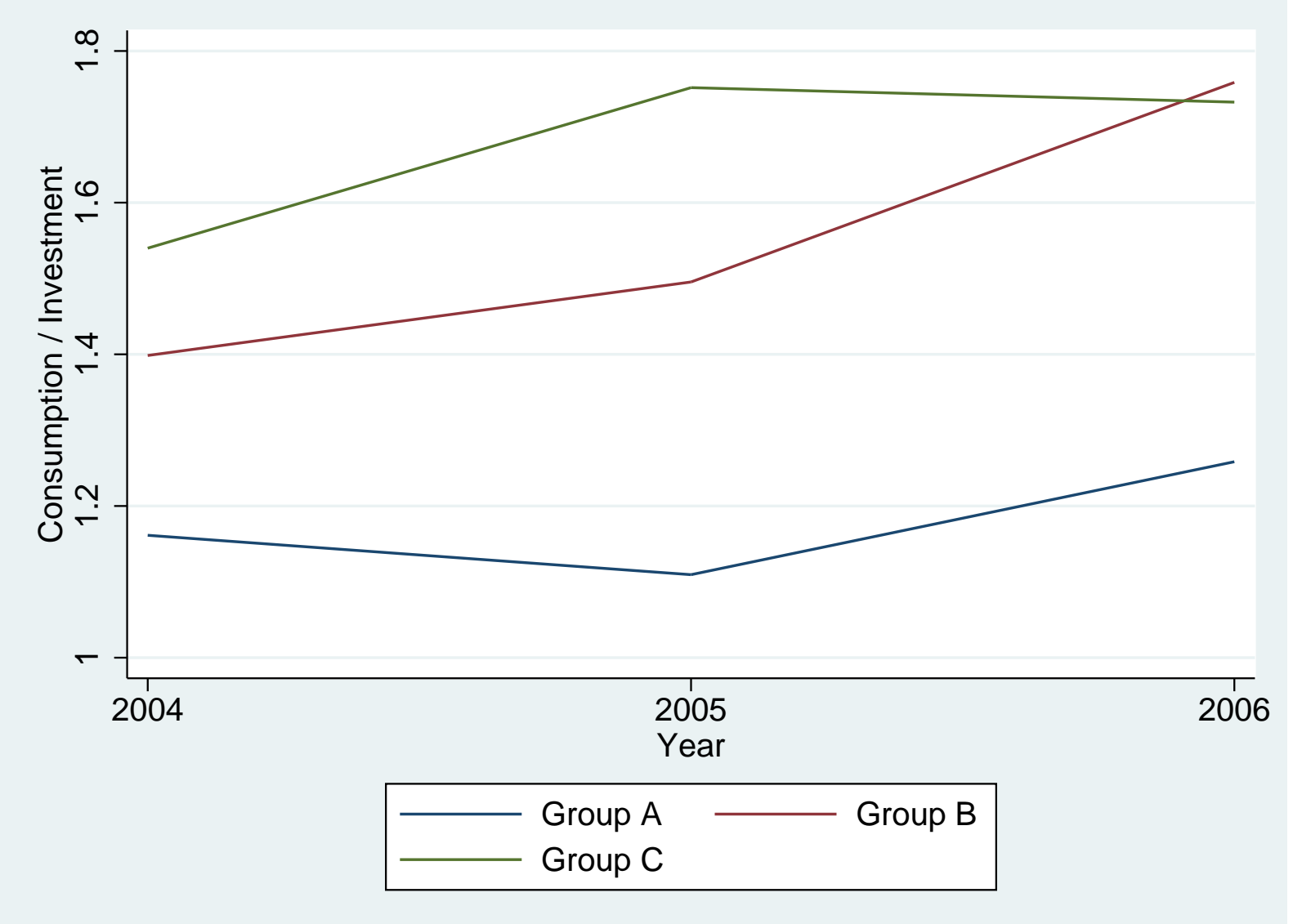

Figure 4: Identification strategy, Case IA and Case IB

\begin{tabular}{|c|ccc|}
\cline { 2 - 4 } \multicolumn{1}{c|}{} & Group A & Group B & Group C \\
\hline $\mathrm{t}_{1}$ & no & no & yes \\
$\mathrm{t}_{2}$ & no & yes & yes \\
$\mathrm{t}_{3}$ & no & no & yes \\
\hline
\end{tabular}

Figure 5: Identification strategy, Case IIA and Case IIB

\begin{tabular}{|c|c|c|c|}
\hline & Group A & Group B & Group C \\
\hline $\mathrm{t}_{1}$ & no & no & yes \\
\hline $\mathrm{t}_{2}$ & no & yes & yes \\
\hline $\mathrm{t}_{3}$ & no & no & \\
\hline
\end{tabular}


Figure 6: Difference-in-discontinuities in Case I. Threshold at 3,000 inhabitants. The central line is a SPA of order 2 and the later lines represent the $95 \%$ confidence interval. Scatter points are averaged over intervals of 50 inhabitants. On the vertical axis there are the $t_{0^{-}} t_{-1}$ budget values. On the horizontal axis there is the actual population size.

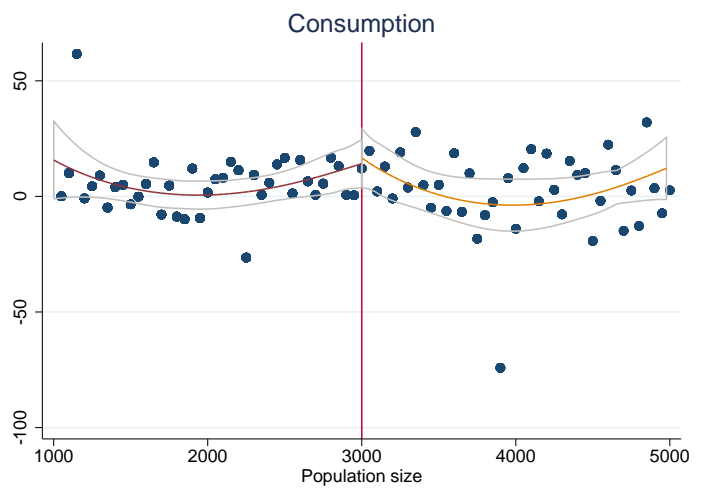

(a) Case IA

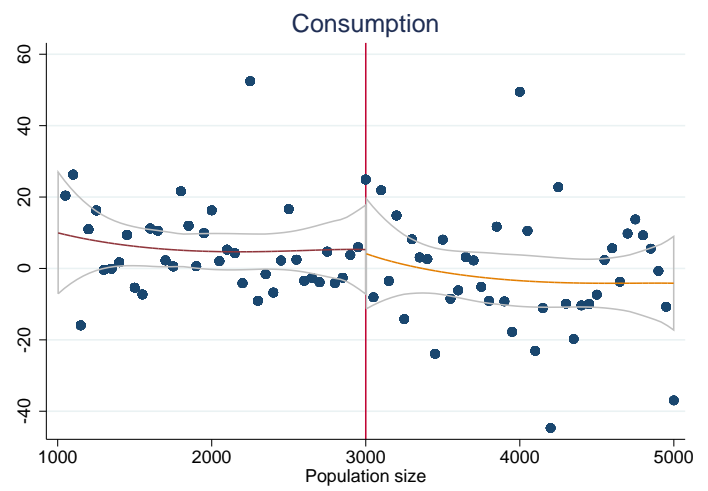

(c) Case IB

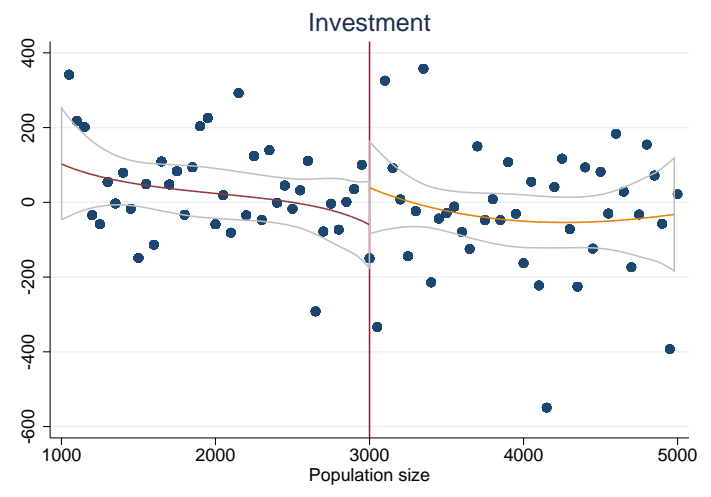

(b) Case IA

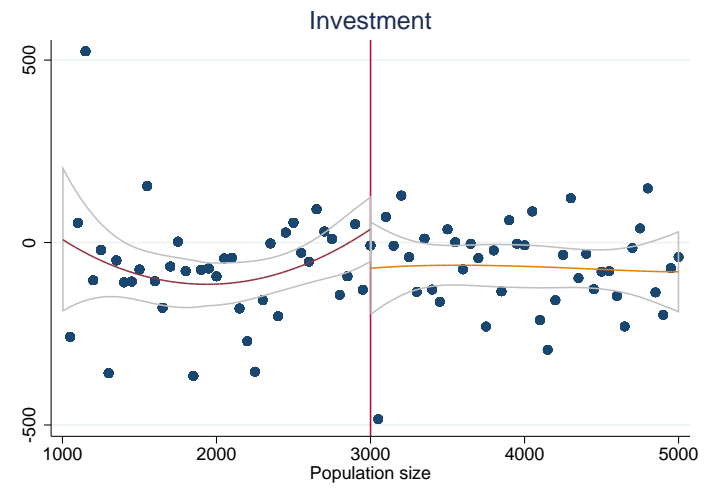

(d) Case IB 
Figure 7: Difference-in-discontinuities in Case II. Threshold at 5,000 inhabitants. The central line is a SPA of order 2 and the later lines represent the $95 \%$ confidence interval. Scatter points are averaged over intervals of 50 inhabitants. On the vertical axis there are the $t_{0}-t_{-1}$ budget values. On the horizontal axis there is the actual population size.

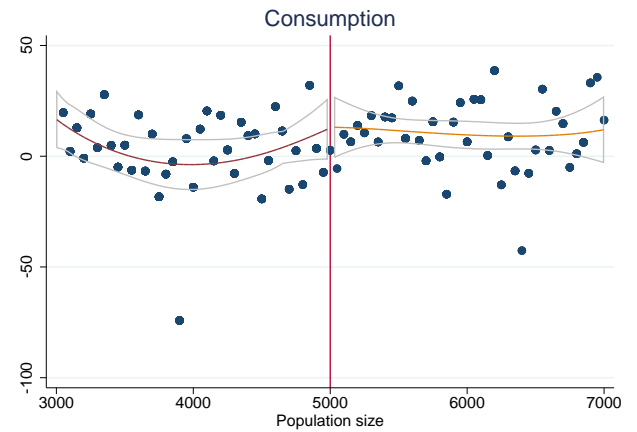

(a) Case IIA

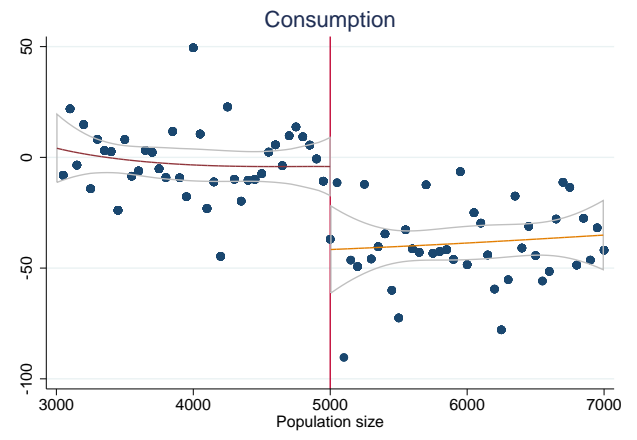

(c) Case IIB

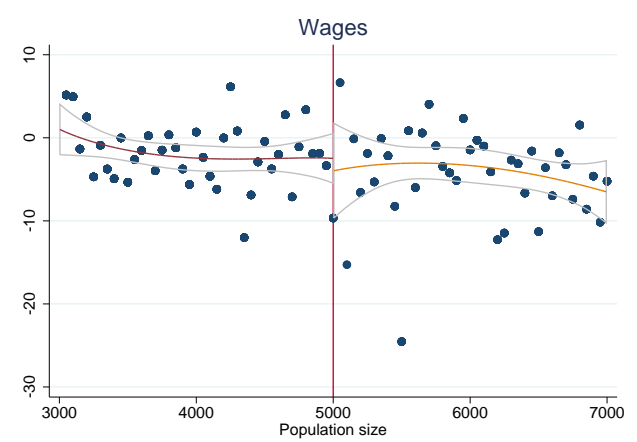

(e) Case IIB

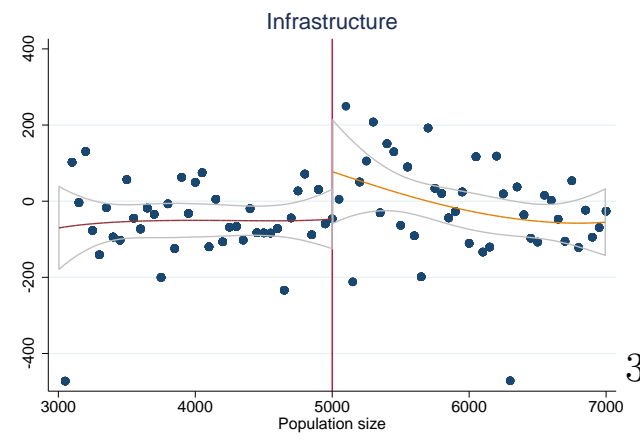

(g) Case IIB

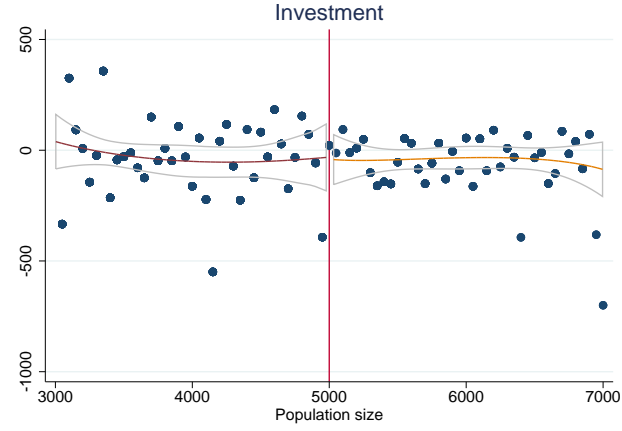

(b) Case IIA

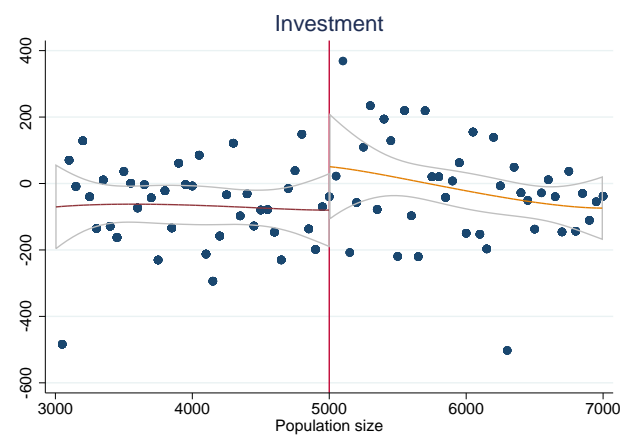

(d) Case IIB

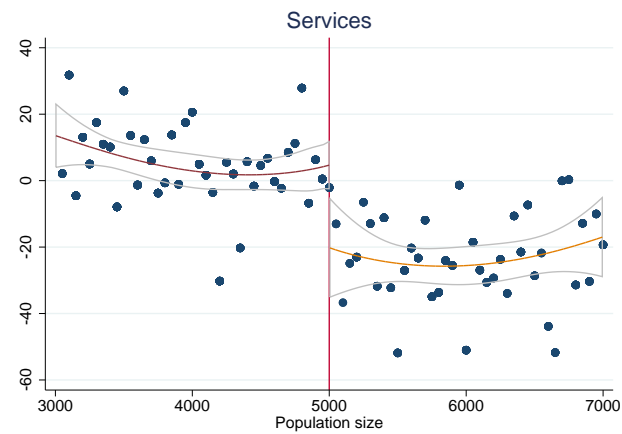

(f) Case IIB

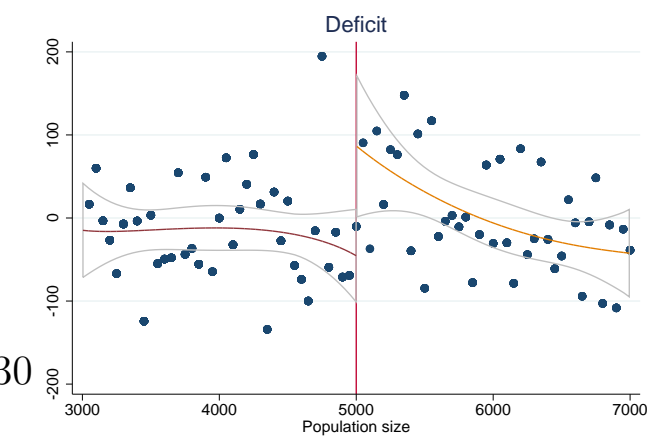

(h) Case IIB 


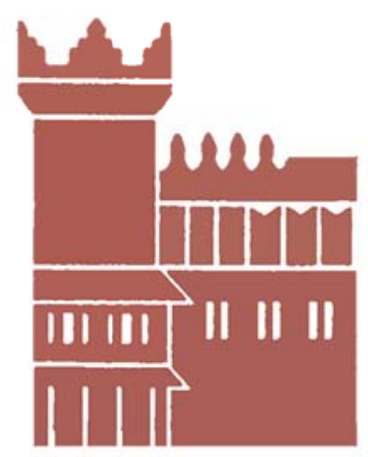

Alma Mater Studiorum - Università di Bologna DEPARTMENT OF ECONOMICS

Strada Maggiore 45

40125 Bologna - Italy

Tel. +39051 2092604

Fax +390512092664

http://www.dse.unibo.it 